\section{Rotation of a Lamina Falling in Air.}

IN your issue of March 20, Dr. Johnstone Stoney, in reference to the behaviour of ice spiculæ in the clouds, instances the spinning of a card when dropped through the air.

I think Lord Rayleigh was the first person to point out how curious this phenomenon is and to show that the axis of a spinning lamina might be held between bearings without affecting the result. Also that a lamina so held and placed in a draught was equally ready to spin in either direction, thus precluding the idea that the rotation might be due to some want of symmetry in the lamina itself.

A few years ago I made some experiments on the rotation of laminæ in air currents.

The laminæ were mounted in bearings as frictionless as I could make them, and the experiment consisted $(a)$ in measuring the speed of the air and the angular rotation of the lamina, $(b)$ in mapping the flow of the air past the lamina. This was done by the use of smoke and intermittent illumination.

It would take too long to describe the apparatus in detail, but some of the results may be of sufficient interest for publication.
To calculate the magnitude of the couple prior $i$ is, 1 believe, beyond the power of mathematical analysis at present.

The experiments just alluded to were made with light rectangular laminæ, but these conditions are not essential-pennies spin very nicely when dropped from a great height.

I have not succeeded in making a lamina spin in a current of water, probably because the densities of the fluid and solid are not sufficiently different, but if a flywheel were fixed on the axis of the lamina, so as to be out of the water, and thus increase the moment of inertia of the turning body without altering the fluid friction, \&c.; rotation might perhaps be obtained in this case also.

March 22.

\section{Mathematics and Science at Cambridge.}

To those who have at heart the advancement of scientific knowledge in Great Britain it is impossible but to acknowledge that the country owes a profound debt of gratitude to the University of Cambridge. During the dark ages of education her colleges formed the stronghold of modern culture; and the
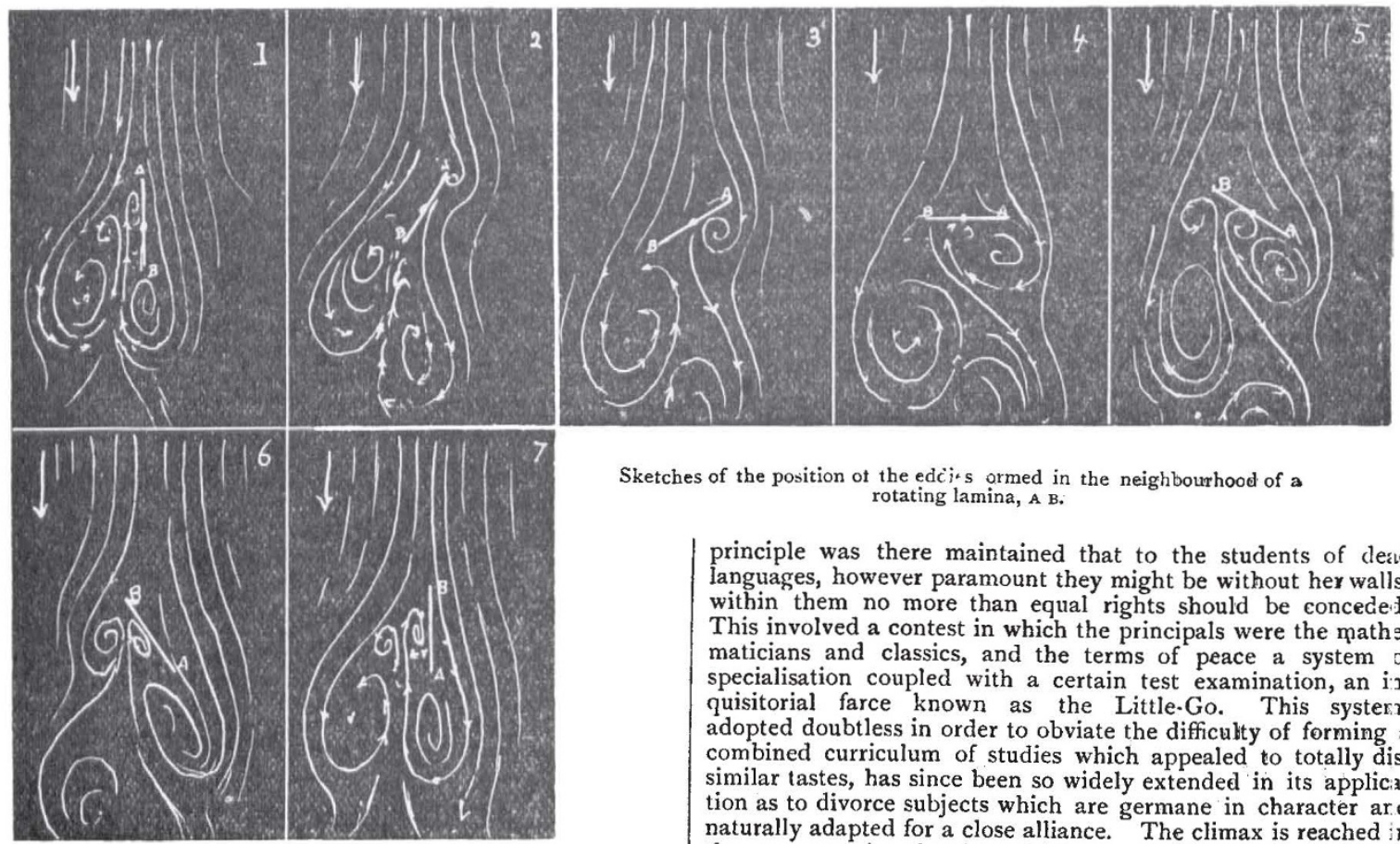

Sketches of the position ot the edcits ormed in the neighbourhood of a rotating lamina, A B.

principle was there maintained that to the students of clead languages, however paramount they might be without her walls, within them no more than equal rights should be conceded. This involved a contest in which the principals were the mathematicians and classics, and the terms of peace a system of specialisation coupled with a certain test examination, an ijquisitorial farce known as the Little-Go. This systern, adopted doubtless in order to obviate the difficulty of forming a combined curriculum of studies which appealed to totally dissimilar tastes, has since been so widely extended in its applic:3tion as to divorce subjects which are germane in character ard naturally adapted for a close alliance. The climax is reached in the ever-growing barrier which separates mathematics from natural science, and which is year by year made more impassable by the examinations for entrance scholarships. These are of high value; and without this aid from the funds which the college authorities hold in trust for educational purposes many a brilliant man would be unable to consummate his work at school by a university career. It is, therefore, necessary that school curricula should be arranged in strict accordance with their requirements.

In view of their future careers, schoolboy mathematicians are divisible roughly into three classes-those who will make a profession of mathematics, those who will apply mathematics to science, and those who will, after obtaining academic honours, entirely sever their connection with the subject. To the last of these the question of syllabus is of comparatively small im. portance. But to the first and second it is of the utmost importance, and especially to the second, as it is essential to a man who for several years studies mathematics with an ulterior object in view that, while he should acquire a thorough grasp of the principles of the subject, he should not be forced by examining bodies to apply himself to what can only be regarded as intellectual pastimes : nor even in the case of the first can great skill in work of this class rank pari passu with a grasp of principle.

NO. I692, VOL. 65] 